\title{
AVALIAÇÃO NEOLIBERAL E AVALIAÇÃO CONTRA-HEGEMÔNICA
}

José Eustáquio Romão ${ }^{(*)}$

Há tantas concepções de avaliação da aprendizagem quantos são seus formuladores. Há pouco mais de uma década, era tarefa fácil levantá-las, pois podia se contar nos dedos de uma mão o número de obras publicadas, pelo menos em Português, sobre o tema. Hoje, a tarefa se tornou mais difícil dado o fato de que avaliação virou um tema da moda. Muita gente tem escrito sobre ele e se tentasse reunir todos os títulos, seriam necessárias algumas malas. Contudo, essa multiplicidade conceptual exprime-se por meio de diferenças secundárias, mais de forma do que de substância. É que, cada concepção de avaliação fundamenta-se em uma visão de educação e esta, por sua vez, referencia-se em uma visão de mundo. Ora, as visões de mundo, enquanto elaborações de grupos sociais privilegiados (classes) ${ }^{1}$ ocorrem em número reduzido em cada formação social.

Acrescentemos somente que as visões de mundo, sendo a expressão psíquica da relação entre certos grupos humanos e seu meio social e natural, seu número é, por um longo período histórico, necessariamente limitado. [...] Por mais múltiplas e variadas que sejam as situações históricas concretas, as visões de mundo não exprimem mais que a reação de um grupo de seres relativamente constantes a esta multiplicidade de situações reais (GOLDMANN, 1959, p. 29-30)².

Assim, se as formulações pessoais, que exprimem caracteres idiossincráticos em contextos variados, são muitas, substantivamente, as concepções são poucas, na medida em que são reproduções simbólicas homólogas ${ }^{3}$ da consciência da classe social a que pertencem seus formuladores. Em suma, o que estamos querendo dizer é que um conceito de avaliação da aprendizagem fundamenta-se em uma concepção de educação e esta tem suas referências na visão de mundo da classe social de seu autor. Como as classes sociais são poucas, as visões de mundo e as concepções de educação delas derivadas existem, também, em número reduzido. Ora, como a

\footnotetext{
${ }^{(*)}$ Graduado em História e Doutorado em Educação (1996), pela USP. Diretor fundador do Instituto Paulo Freire e Diretor e Professor do Programa de Pós-Graduação em Educação (Doutorado e Mestrado), na Universidade Nove de Julho (UNINOVE).

${ }^{1}$ Segundo Lucien Goldmann, ao longo de toda sua obra e, mais especificamente, em Le Dieu Caché (1959: 13 e seguintes). No sentido goldmanniano, classe social não são todos os grupos que se fundam em interesses econômicos comuns, mas os que direcionam estes interesses para a transformação ou manutenção da estrutura global da sociedade.

2 Tradução de J. E. Romão.

${ }^{3}$ É também Lucien Goldmann quem faz a importante distinção entre “analogia” e "homologia”. A primeira opera por reflexo; a segunda, por reprodução, na superestrutura, do que ocorre nos níveis infraestruturais.
} 
cada concepção de educação corresponde uma concepção de avaliação da aprendizagem, não é muito difícil construir uma tipologia das concepções de avaliação em um número reduzido.

Sem querer repetir o maniqueísmo tão frequente nas obras que tratam de avaliação educacional entre nós, que oscilam entre uma concepção “mais avançada” (“da moda”) e uma “mais tradicional” (“superada”) ${ }^{4}$, propomos uma tipologia dual, com a qual seria possível classificar as concepções de avaliação da aprendizagem que mais estão pressionando a educação básica no Brasil.

Qualquer fenômeno cultural $^{5}$ pode ser submetido à avaliação, ou seja, toda ação humana deve ser avaliada para orientar os processos de tomada de decisão, no sentido da busca de correção de rumos (objetivos, estratégias ou procedimentos), como escreveu Luckesi (1995). Sob esta concepção, a constatação e análise dos equívocos, dos erros e dos mal-entendidos têm mais valor do que a verificação dos acertos, pois estes últimos já eram previstos e esperados das performances submetidas à avaliação. Neste aspecto, ela pode ser considerada como diagnóstica, na medida em que se volta para o levantamento de dificuldades de determinado desempenho humano que, uma vez constatadas, recebem um tratamento, para serem superadas. Neste caso, ela visa à inclusão do agente no universo dos que lograram êxito no mesmo desempenho.

Lamentavelmente, a avaliação tem se voltado mais para a reiteração dos acertos, porque tem estado mais a serviço da meritocracia, da discriminação e, no limite, da exclusão. Ela tem funcionado mais como julgamento, exarando veredictos mortais sobre o desempenho humano dos mais fracos, dos discriminados e dos excluídos. Na sua versão julgadora, ou classificatória, identifica acertos e erros para premiar ou punir seus respectivos agentes, confirmando sua teleologia excludente em relação aos últimos. Em suma, a avaliação pode funcionar como diagnóstico, ou como exame; como pesquisa, ou como classificação; como instrumento de inclusão, ou de exclusão; como canal de ascensão social, ou como critério de discriminação.

Seja em que versão for, ela sempre carrega consigo uma dimensão classificatória: mesmo que se compare a qualidade do desempenho de alguém a partir da verificação dos impactos de um processo de aprendizagem; Isto é, ainda que se compare momentos diferentes da performance da mesma pessoa, sem comparações com as trajetórias de outros, haverá sempre uma dimensão classificatória. Quando se indaga se o aluno “avançou” em relação ao desempenho que apresentava anteriormente, após um processo de aprendizagem, a própria pergunta carrega consigo um ponto de

\footnotetext{
${ }^{4}$ Do qual já tratei mais detalhadamente em Avaliação dialógica (ROMÃO, 1998).

${ }^{5}$ Entendendo-se por cultura a humanização da natureza ou tudo que é processo ou produto da ação humana, nos termos da antropologia clássica.
} 
chegada desejável. Afinal, ele “avançou” para onde? Para a verificação de seus avanços em relação às suas próprias situações anteriores, é necessário compará-los a padrões desejáveis e previamente estabelecidos nos pontos para os quais "ele avançou”6. Portanto, mesmo na sua dimensão diagnóstica, a avaliação apresenta sempre um viés comparativo, classificatório. Da mesma forma, pode-se dizer que toda avaliação carrega consigo uma dimensão diagnóstica, já que, mesmo que o avaliador não disponha de recursos nem de vontade para ajudar os que apresentaram mau desempenho, a constatação das fragilidades potencializa correções.

Contudo, a predominância de uma ou outra dimensão depende do contexto. Como vivemos em uma sociedade dominada pelo modo de produção cuja tendência estrutural é a produção e reprodução de uma sociedade meritocrática, discriminatória e, no limite, excludente, a dimensão avaliativa aí predominante é a classificatória. Este tipo sociedade opera, simultaneamente, com promessas de abertura de canais de ascensão social, com proclamações ideológicas de "igualdade de oportunidades”, mas atua com procedimentos concretos de construção de critérios de discriminação social, que obstruem aqueles canais e esvaziam aquelas promessas e proclamações. Exatamente aí a avaliação passa a desempenhar um papel importante, porque, se aplicada como exame ou julgamento, fundamentará os álibis do débito do fracasso na conta do próprio "fracassado".

Como a avaliação da aprendizagem realizada pelos Estados Burgueses tem sido apelidada de “exames”, Cipriano Luckesi propôs uma distinção que trai o significado original dos termos. Avaliar significa atribuir valor; examinar significa verificar para encontrar causas de um mal, que deve ser diagnosticado e tratado. Ora, “exame”, então, estaria mais próximo da concepção diagnóstica, que visa a incluir; enquanto avaliação apontaria mais para a avaliação quantitativista e, portanto, classificatória. Assim, enquanto o termo “avaliação” deveria ser adstrito a uma concepção específica de verificação do desempenho humano, mais preocupada com a política da exclusão, o vocábulo “exame” seria mais apropriado para as verificações voltadas para a identificação e inclusão dos “menos capazes”. Luckesi propôs exatamente o contrário, por causa da denominação “exames nacionais” atribuída às avaliações externas realizadas pelos poderes públicos e que têm um caráter nitidamente classificatório, voltado para os rankings e os índices ${ }^{7}$.

\footnotetext{
${ }^{6}$ Tratei desse aspecto mais detalhadamente em Avaliação dialógica, especialmente no capítulo 4 (p. 55 e seguintes). O mal do maniqueísmo não está em perceber duas concepções de avaliação, mas em contrapô-las radicalmente, como mutuamente excludentes, conforme tentamos demonstrar nessa mesma obra.

${ }^{7}$ Cipriano Luckesi expôs na mesa-redonda, de que também participamos, no II Fórum Nacional de Educação, realizado em São Luís (MA), em 13 de junho de 2002, a diferença entre “avaliação” e “exame”, ligando primeira à avaliação inclusiva e o segundo à avaliação excludente.
} 
As duas concepções - diagnóstica e classificatória - têm estado presentes nas diversas modalidades de avaliação que pontuaram (e pontuam) a educação brasileira, com uma clara predominância, infelizmente, da última.

\section{MODALIDADES DE AVALIAÇÃO}

Por modalidades entendemos os campos educacionais em que a avaliação tem sido aplicada. Seja na sua vertente diagnóstica, seja na classificatória, a avaliação educacional, no Brasil, tem se manifestado sob três modalidades básicas:

I - avaliação da aprendizagem;

II - avaliação de desempenho;

III - avaliação institucional.

Apenas para não passar em branco, serão registradas algumas poucas palavras sobre as duas últimas modalidades, para nos concentrarmos na que interessa aos propósitos deste trabalho, que é a avaliação da aprendizagem, especialmente aquela que se dá, formalmente, na escola.

A avaliação do desempenho tem sido considerada instrumento de verificação das performances docentes e tem sido recebida com toda a resistência possível e imaginável, porque os docentes temem que a avaliação de seu desempenho seja mais um instrumento de construção de critérios profissionais discriminatórios por chefias autoritárias.

É bom lembrar que o "furor avaliativo" dos últimos anos, com a criação e implantação dos "sistemas nacionais de exames”, com testes padronizados, rankings e indicadores quantitativistas (PISA, IDEB, IDESP etc.) e premiação (bônus) ou punição, nos termos da cartilha neoliberal, revela um enorme equívoco: o principal fator da melhoria da aprendizagem, seja do ponto de vista quantitativo, seja do qualitativo, depende, fundamentalmente, do fator humano. Ora, o modelo de avaliação predominante nos sistemas nacionais de exames desconfia, sobretudo, dos professores, submetendo-os aos vexaminosos processos de avaliação padronizada e "rankiada", ameaçando-os com punições na carreira e cooptando-os com os chamados "bônus”. Nada mais contrário aos resultados positivos de uma avaliação qualitativa. Conforme demonstrou Luiz Carlos de Freitas, no Seminário Internacional sobre Diretrizes Conceituais e Operacionais para a Avaliação na Educação Básica, promovido pelo Conselho Nacional de Educação, em outubro de 2011, a aplicação da “cartilha neoliberal” ipsis litteris e que tem neste tipo de avaliação sua mais poderosa arma de desconfiança e intimidação de docentes, revelou seu mais profundo fracasso, como se pode 
comprovar nos sistemas nacionais de educação dos países que se alinharam às diretrizes dos chamados, por ele, “reformadores empresariais da educação”.Já os países que não se alinharam a essas diretrizes, tiveram muito sucesso, como é o caso da Finlândia. Ainda segundo o Professor Luiz Carlos de Freitas, esta deve ser a razão pela qual, tanto os que fracassaram quanto os que tiveram sucesso, sumiram da grande imprensa: os primeiros, porque são a prova positiva da inadequação do projeto neoliberal de educação; os segundos, porque são a prova negativa dessa mesma inadequação.

A expressão avaliação institucional tem sido atribuída aos recentes esforços que vêm sendo despendidos na busca do “estado da arte” das instituições educacionais, especialmente as de ensino superior. A avaliação institucional tem sido entendida como processo de verificação da satisfação dos agentes internos e do sucesso dos egressos de uma unidade escolar ${ }^{8}$.

Nesta modalidade de avaliação, os intelectuais orgânicos desta nova fase da acumulação capitalista têm recomendado, também, a avaliação padronizada, os rankings, os indicadores etc. Cabe, aqui, uma pequena reflexão sobre indicadores na educação. Estamos convencidos de que a melhor posição, ou melhor, desconfiança, em relação aos indicadores é a que foi elaborada por José Beltrán Llavador, no contexto da Rede Ibero-Americana de Investigação em Políticas Educativas (RIAIPE) $^{9}$, da qual o autor deste capítulo participa: em vez de elaborarmos indicadores alternativos aos indicadores economicistas hegemônicos, não deveríamos elaborar alternativas aos indicadores?

\section{AVALIAÇÃO DO RENDIMENTO ESCOLAR}

Muito se tem escrito sobre esta modalidade de avaliação nos últimos anos, por um lado; por outro, também recentemente, tem-se importado uma razoável literatura ${ }^{10}$ sobre o tema.

Mesmo assumindo a postura diagnóstica, ela tem encontrado resistências, já que a verificação da “melhoria” sempre implica uma comparação com valores, projeções e ideais socialmente sancionados. E é somente neste sentido que podemos compreender a reação docente em relação à implantação de ciclos no ensino fundamental brasileiro. De uma maneira generalizada

\footnotetext{
8 Seria desejável, mas ainda não tivemos a oportunidade de assistir à avaliação dos sistemas educacionais e, principalmente, à dos órgãos gestores, como Secretarias de Educação e o próprio Ministério da Educação e do Desporto. Este tipo de avaliação, a população a faz indiretamente, por meio dos processos eleitorais dos mandatários que escolhem os dirigentes desses órgãos.

${ }^{9}$ Posteriormente, José Beltrán Llavador, refez o texto apresentado no seminário realizado em Barcelona e, juntamente com Alícia Villar Aguilés, escreveu um artigo para o dossiê “Educação na Ibero-América”, que foi publicado na revista Educação e Linguagem, n. 21 (2010), da Universidade Metodista de São Paulo.

${ }^{10}$ Às vezes de discutível qualidade.
} 
e por muitos anos, os professores vêm debitando na conta do "sistema" suas dificuldades com a avaliação dialógica, construtivista, emancipatória ou diagnóstica. Nas intenções proclamadas, na maioria das vezes, afirmam que gostariam de aplicar avaliações "mais corretas” e "mais justas” e que “o sistema não as permite”, dadas suas exigências de promoção seriada, que acabam determinando procedimentos avaliadores meritocráticos, seletivos e discriminatórios. Porém, as tentativas de desseriação, que eximem os professores das avaliações classificatórias anuais, abrindo espaço para os diagnósticos - afinal, não há que se classificar o aluno com tanta frequência para a série subsequente à que se encontra -, acabaram encontrando forte resistência. Certamente as razões da resistência são mais complexas ${ }^{11}$.

Na sua versão classificatória, os processos avaliativos têm encontrado resistências de todos os lados e em todos os níveis, com questionamentos à sua legitimidade científica e política, porque quase sempre é percebida como ameaça de discriminação e de exclusão.

A avaliação da aprendizagem diz respeito à verificação dos desempenhos discentes, como se apenas eles fossem os aprendizes na relação pedagógica ${ }^{12}$. É a mais tradicional entre nós e, praticamente, está nas origens da implantação da educação formal no Brasil, com os jesuítas, já que os padres da Companhia de Jesus, ao desembarcarem no Brasil, em 1548, embora ainda não tivessem no bolso da batina seu método de ensino ${ }^{13}$, já praticavam a avaliação competitiva em seus colégios nos cinco continentes. Aliás, a meritocracia era uma característica da rígida pedagogia inaciana.

Outra característica do ensino jesuítico é a emulação, ou seja, o estímulo à competição entre os indivíduos e as classes. [...] Os alunos que mais se destacam são incentivados à emulação com prêmios concedidos em solenidades pomposas, para as quais são convocadas as famílias, as autoridades eclesiásticas e civis, a fim de dar-lhes brilho especial (ARANHA, 2001, p. 93).

Com a “cultura da repetência” - feliz expressão de Sérgio Costa Ribeiro, de saudosa memória - implantada no sistema educacional brasileiro, certamente chegamos a ser um dos países

\footnotetext{
${ }^{11}$ Conforme demonstrou Darvim Nunes de Carvalho, em sua dissertação de Mestrado (2001), defendida no Programa de Mestrado em Educação do Centro Universitário Nove de Julho (UNINOVE), ao examinar a questão em escolas paulistanas.

${ }^{12}$ Numa perspectiva freiriana, o ato de ensinar é, simultânea e essencialmente, de aprendizagem também e vice-versa.

${ }^{13}$ Ratio atque Institutio Studiorum (Organização e plano de estudos) foi resultado da codificação e consolidação das experiências pedagógicas dos jesuítas feita pelo padre Aquaviva. É interessante observar a rapidez da expansão da Companhia de Jesus: criada em 1534, pelo militar espanhol, Inácio de Loyola, e oficialmente aprovada seis anos depois, pelo papa Paulo III, esta ordem religiosa já mandava seus "soldados” para o Brasil, em 1549, com o primeiro Governador Geral, Tomé de Souza. E, exatamente uma década depois, já possuía quase uma centena e meia de colégios espalhados por todo o mundo.
} 
que mais reprovava alunos da educação básica no mundo! A escola era considerada boa, assim como o professor, quando eram ambos “rígidos”, "rigorosos”, isto é, reprovavam muito. O mesmo não ocorria no ensino superior, no qual a reprovação, em muitos cursos, foi praticamente banida, numa completa inversão do que ocorre em outros países. Pelo que se pode perceber, ao contrário do que acontece fora daqui - ingresso fácil no ensino superior, com difícil saída -, no Brasil são interpostas várias barreiras à entrada na universidade, mas, uma vez lá dentro, não há praticamente mais nenhum obstáculo a ser transposto até a saída. No nível de escolarização básica - do qual se espera que a pessoa seja apenas preparada para viver no mundo de sua época -, fazemos julgamentos rigorosos e irreversíveis sobre seu desempenho escolar. Já no nível superior - em que os alunos são preparados para, profissionalmente, interferirem na vida de várias outras pessoas - a avaliação não reprova. E não se pense que aqui ela seja menos classificatória e mais diagnóstica; a distensão da avaliação aí ocorre por cumplicidades dodiscentes ${ }^{14}$, que banalizam as relações acadêmicas e abastardam o rigor científico.

As recentes tentativas de combate à “cultura da repetência” no Ensino Fundamental ${ }^{15}$ resvalaram para a eliminação da "reprovação por decreto", na chamada "promoção automática”. Lamentavelmente, nesse contexto educacional, o sistema de promoção é aparentemente eliminado com a desseriação, mas, na verdade, ele é mantido, com a promoção automática; elimina-se, aí, apenas a reprovação. Essa distorção é a verdadeira “crônica da morte anunciada” de uma das melhores ideias que já surgiram, nos últimos anos, na educação brasileira. O despreparo dos docentes para a nova realidade e, principalmente, sua não participação no processo de formulação dos ciclos está ajudando a acelerar o sepultamento dessa boa concepção.

Na verdade, o que está provocando toda a fragilização é a falta de aprofundamento da discussão sobre a avaliação da aprendizagem, verdadeiro nó górdio da educação brasileira. As interpretações enviesadas do sistema de ciclos estão quase sempre vinculadas a distorções na concepção de avaliação. O trabalho de Carvalho (2001, mimeo.) demonstrou que a implantação dos ciclos nas escolas públicas paulistanas acabou por soterrar a autoestima do professor, já que sua autoridade passou a ser completamente desrespeitada: com a promoção automática, os alunos passaram a não mais atender às solicitações e determinações dos docentes, especialmente às tentativas de aplicação de instrumentos de avaliação e, em casos limites, passaram até mesmo a não

\footnotetext{
${ }^{14}$ Uso aqui o neologismo criado por Paulo Freire, que o forjou para traduzir, linguisticamente, a unidade indissociável entre $\mathrm{o}$ ato de aprender e o de ensinar.

${ }^{15}$ Uso as maiúsculas por entender que os graus de ensino previstos na legislação brasileira ganharam denominações específicas que devem ser grafadas com substantivos próprios.
} 
mais frequentar as aulas. A visão introjetada nos alunos, de que a avaliação visa apenas à promoção e que está proibida a reprovação, é certamente o que os levou a agir dessa forma. Contudo, quem “inventou” esta visão foi a própria escola, ou melhor, os agentes profissionais que nela trabalham. Por isso, a desseriação necessita também uma cuidadosa preparação dos usuários do sistema escolar para a compreensão do significado da verificação da aprendizagem dialógica.

Pais e demais usuários da rede de educação formal, também com uma visão distorcida de avaliação (seletiva), reagem com desconfiança, julgando que a escola não mais ensina, porque promove, com o sistema de ciclos, uma “facilitação”. Tanto esta reação desconfiada quanto aquela astuciosa são resultados de longos anos de disseminação de uma cultura da avaliação sancionadora de prêmios e castigos.

Com certa dose de boa vontade, podemos admitir que os erros de aplicação devam ser debitados na conta da precipitação pela mudança, sem a devida dose estratégica de paciência histórica dos formuladores e gestores dos sistemas de ciclos.

Concluindo estas considerações sobre o campo específico da avaliação do rendimento escolar, devemos retomar algumas reflexões que desenvolvemos em Educação dialógica.

Com uma concepção educacional "bancária” desenvolvemos uma avaliação "bancária” da aprendizagem, numa espécie de capitalismo às avessas, pois fazemos um depósito de "conhecimentos” e os exigimos de volta, sem juros e sem correção monetária, uma vez que o aluno não pode a ele acrescentar nada de sua própria elaboração gnosiológica, apenas repetindo o que lhe foi transmitido. [...] Ao contrário, na escola cidadã, na qual se desenvolve uma educação libertadora, o conhecimento não é uma estrutura gnosiológica estática, mas um processo de descoberta coletiva, mediatizada pelo diálogo entre educador e educando (ROMÃO, 1998, p. 88).

A mediação a que me referia por época de escrita dessa obra não tem o mesmo sendo da mediação (mediatização) de que falava Paulo Freire na Pedagogia do oprimido (op. cit.). O significado que aqui lhe conferimos é o de intermediação, de ponte, de canal de ligação. Já a concepção de Paulo Freire aproxima-se da desenvolvida pelo Materialismo Dialético, segundo o qual o imediato é superado pelo mediato e, neste caso, é o próprio educando quem faz esta superação, “lendo o mundo”, pois segundo ele: “Já agora ninguém educa ninguém, como tampouco ninguém se educa a si mesmo: os homens se educam em comunhão, mediatizados pelo mundo” (FREIRE, 1987, p. 39). 


\section{CONSIDERAÇÕES FINAIS}

Paulo Freire, ao longo de sua obra e, mais especificamente, na última que publicou em vida (Pedagogia da autonomia, 1997), sempre afirmou que o homem (ser incompleto, inacabado e inconcluso) só inicia o processo de plenificação, de acabamento e de autoconclusão de sua humanidade no momento em que toma consciência daquela incompletude. O processo de desalienação inicia-se, então, com a consciência dos próprios limites, ou, com a apreensão crítica da própria realidade alienada. Esta conscientização nada mais é do que um profundo processo de autoavaliação, de verificação da própria ontologia, na medida em que a pessoa se debruça, diagnosticamente, sobre si mesma, na busca da superação dos próprios limites.

Aparentemente, esta constatação constitui uma pobreza ontológica do ser humano em relação aos demais seres da natureza, porque, embora igual a eles na incompletude, diferentemente deles, dela toma ciência. Porém, o que poderia parecer inferioridade, na verdade constitui sua marca distintiva no universo: a tendência estrutural incoercível para a busca de sua completude, por força da insatisfação gerada pela consciência da incompletude - por isso, somente o ser humano é um ente esperançoso e pedagógico. Esperançoso, porque, eternamente insatisfeito com sua condição, busca continuamente a perfeição, a plenitude, o acabamento, a conclusão. Daí a dimensão dinâmica, ativa da esperança, em contraposição à passividade da espera. O ser humano é, também, essencialmente pedagógico, porque a busca da completude o leva, incessantemente, ao ato pedagógico. É da essência do ato pedagógico a dimensão da esperança: quem procura qualquer nicho educativo, busca-o na esperança de ser mais do que é no momento da busca. Em conclusão, o ser humano é um ente ontologicamente auto-avaliador e, ao mesmo tempo, tentado à hétero avaliação, dado que não se completa sozinho, mas - parafraseando Paulo Freire - só se completa em comunhão com os outros, mediatizado pelo mundo. E é aí que ele encontra outro componente importante de sua essencialidade ontológica: a liberdade.

Somente no pensamento conservador, os componentes dos pares liberdade/necessidade histórica, contingente/necessário, sujeito/objeto, presente/futuro, realidade/utopia são dicotômicos. Ao contrário, para os que se inserem no universo dialético, a liberdade começa a se construir quando o ser humano se torna sujeito de sua própria história e isto somente acontece quando ele toma consciência da necessidade histórica, isto é, da correlação de forças históricas. Assim, a liberdade não nega a necessidade histórica, mas se constrói a partir de seu reconhecimento. Também o contingente não é a negação do necessário, mas com ele se imbrica da tessitura do mundo e deve ser assim apreendido criticamente pelos seres humanos. O futuro, da mesma forma, não é a anulação do passado e do presente, mas o resultado das projeções dos dois outros tempos, a 
síntese histórica dos processos, das tendências e das contradições engendrados no passado e no presente. Finalmente, realidade não é obstáculo à utopia, mas sua base, seu patamar de impulso, seu suporte inicial.

Dessa forma, ao se considerar o fenômeno da avaliação, não como há deixar de tomar em conta dois aspectos: o primeiro diz respeito às implicações ontológicas da avaliação; o segundo, à sua historicidade.

Queremos concluir este trabalho com as considerações sobre este último aspecto, porque ele nos parece estratégico numa sociedade como a que se tem tornado hegemônica neste início de século. Numa formação social em que a desigualdade e, no limite, a exclusão constituem sua principal tendência estrutural, a avaliação tende, também estruturalmente, a adotar a lógica do exame, do julgamento, da exclusão. Diante de cada canal de ascensão social, ela tende a criar um critério de discriminação correspondente, para anular as possibilidades criadas por aquele canal. Na verdade, os critérios de discriminação social funcionam como vasos constritores dos canais de ascensão social, também criados pelas sociedades estratificadas verticalmente como álibi ideológico da "igualdade de oportunidades".

Assim, a educação, que é apresentada como canal de ascensão social, tem sua potencialidade equalizadora diminuída, senão anulada, por uma racionalidade seletiva. A avaliação educacional funciona como controle que, de certa forma, levanta barreiras nos canais de inclusão, formalmente abertos a todos. A inclusão é admitida, geralmente, apenas enquanto exceção, e funciona, ao mesmo tempo, como mecanismo de cooptação de alguns poucos egressos das camadas dominadas. Aliás, esta filosofia política, no fundo, esconde a seletividade e debita a exclusão na conta do próprio excluído ${ }^{16}$.

Felizmente, por mais hegemônica que seja a ideologia da meritocracia, da seletividade e da exclusão - que, no fundo, é o fundamento do individualismo burguês - e seus procedimentos correspondentes encontram-se em movimento dialético, ou seja, apresentam-se, ao mesmo tempo, como necessários e contingentes. Necessários porque decorrente da gênese e evolução da correlação de forças históricas desfavoráveis à solidariedade; contingente, porque são reversíveis e, portanto, podem ser mudados pela força da utopia dos que miram o futuro lendo o passado e o presente.

\footnotetext{
${ }^{16}$ Basta atentar, por exemplo, para os discursos das autoridades da República que atribuem aos próprios trabalhadores a culpa de estarem na condição de “inimpregáveis”, com base no argumento de que não cuidaram de sua requalificação para se manterem “competitivos” no mercado de trabalho.
} 


\section{REFERÊNCIAS}

AMORIM, Antônio. Avaliação institucional da universidade. São Paulo: Cortez, 1992.

ARANHA, Maria Lúcia de Arruda. História da educação. 2. ed. rev. atual. São Paulo: Moderna, 2001.

BLOOM, Benjamin S. et al.Taxionomia dos objetivos educacionais: domínio cognitivo. Porto Alegre: Globo, 1972.

Taxionomia dos objetivos educacionais: domínio afetivo. Porto Alegre: Globo, 1974.

BRADFIELD, James M.; MOREDOCK, H. Stewart. Medidas e testes em educação. Rio de Janeiro: Fundo de Cultura, 1963 (2. v.).

CARVALHO, Darvim Nunes de. Avaliação e desseriação: o impacto da implantação dos ciclos no ensino público de São Paulo. Dissertação (Mestrado em Educação) - Universidade Nove de Julho, São Paulo, 2001.

CISESKI, Ângela Antunes; ROMÃO, José Eustáquio. Conselhos de escola: coletivos instituintes da Escola Cidadã. In: GADOTTI, Moacir; ROMÃO, José Eustáquio. (Org.). Autonomia da escola: princípios e propostas. São Paulo: IPF/Cortez, 1997. p. 65-74.

COSTA, Messias. O rendimento escolar no Brasil e a experiência de outros países. São Paulo: Loyola, 1990.

DALBEN, Ângela Imaculada Loureiro de Freitas. Trabalho escolar e conselho de classe. Campinas: Papirus, 1992.

DEMO, Pedro. Avaliação qualitativa. São Paulo: Cortez/Autores Associados, 1987. (Col. Polêmicas do nosso tempo, 25).

FREIRE, Paulo. Educação como prática da liberdade. 18. ed. Rio de Janeiro: Paz e Terra, 1983.

Pedagogia da autonomia: Saberes necessários à prática pedagógica. 3. ed. Rio de Janeiro: Paz e Terra, 1997. (Col. "Leitura”).

Pedagogia da esperança: um reencontro com a Pedagogia do oprimido. Rio de Janeiro: Paz e Terra, 1992.

Pedagogia do oprimido. 10. ed. Rio de Janeiro: Paz e Terra, 1981.

FUNDAÇÃO GETÚLIO VARGAS. Testes e medidas na educação. Rio de Janeiro: FGV/ISOP, 1970.

GADOTTI, Moacir. Diversidade cultural e educação para todos. Rio de Janeiro: Graal, 1992a.

Organização do trabalho na escola. São Paulo: Ática, 1993.

GOLDMANN, Lucien. Ciências humanas e filosofia. São Paulo: DIFEL, 1972a.

A criação cultural na sociedade moderna. São Paulo: DIFEL, 1972 b.

Dialética e ciências humanas. Lisboa: Presença, 1972 (v. I e II).

Épistémologie et philosophie politique. Paris: Denoël/Gonthier, 1978.

Recherches dialectiques. Paris: Gallimard, 1980.

GRAMSCI, Antonio. Obras escolhidas. São Paulo: Martins Fontes, 1978.

HAYDT, Regina Cazaux. Avaliação do processo ensino-aprendizagem. São Paulo: Ática, 1988.

HOFFMANN, Jussara. Avaliação: mito e desafio; uma perspectiva construtivista. 6. ed. Porto Alegre: Educação e Realidade, 1992.

Avaliação mediadora: uma prática em construção - da pré-escola à universidade. 4. ed. Porto Alegre: Educação e Realidade, 1994.

LLAVADOR, José Beltrán; Alícia Villar Aguilés. La medida de la educación: algunas consideraciones a propósito de los indicadores. In: Educação e Linguagem, v. 13, n. 21, p. 131-149, jan./jun. 2010.

LIMA, Adriana de Oliveira. Avaliação escolar: julgamento x construção. Petrópolis: Vozes, 1994.

LUCKESI, Cipriano C. Avaliação da aprendizagem escolar. São Paulo: Cortez, 1995.

LÜDKE, Menga; MEDIANO, Lélia. (Coord.). Avaliação na escola de $1^{\circ}$ grau: uma análise sociológica. Campinas: Papirus, 1992.

MARTINS, Octavio. A medida em psicologia e em educação. In: FUNDAÇÃO GETÚLIO VARGAS/ISOP. Testes e medidas na educação. Rio de Janeiro: FGV/ISOP, 1970. p. 1-22. 
PPGE-UFES. Avaliação educacional: necessidades e tendências. Vitória: PPGE UFES, 1984.

ROMÃO, José Eustáquio. Avaliação dialógica. São Paulo: Cortez/IPF, 1998 (“Guia da Escola Cidadã, 2).

SANT’ANNA, Ilza Martins. Por que avaliar? Como avaliar? Petrópolis: Vozes, 1995.

SAUL, Ana Maria. Avaliação emancipatória: desafio à teoria e à prática da avaliação e reformulação de currículo. 2. ed. São Paulo: Cortez/Autores Associados, 1991.

SILVA, Céres Santos da. Medidas e avaliação em educação. Petrópolis: Vozes, 1992.

SIMPSON, Ray H. La Autoevaluación del maestro. Buenos Aires: Paidós, 1967.

SNYDERS, Georges. A alegria na escola. São Paulo: Manole, 1988. 1996.

. Alunos felizes: reflexões sobre a alegria na escola a partir de textos literários. Rio de Janeiro: Paz e Terra,

SOUSA, Clarilza Prado de. (Org.). Avaliação do rendimento escolar. 2. ed. Campinas: Papirus, 1993.

VASCONCELLOS, Celso dos S. Avaliação: concepção dialética-libertadora do processo de avaliação escolar. 4. ed. São Paulo: Libertad, 1994. (Cadernos Pedagógicos do Libertad, v. 3).

VILLAS BOAS, Benigna Maria de Freitas. (Org.). Avaliação formativa: práticas inovadoras. Campinas, SP: Papirus, 2011. 


\section{RESUMO}

Depois que se tornou um tema da moda (a partir do início da década de 1990), a avaliação implantou-se em quase todos os países do mundo, sob a hegemonia da concepção somativa ou classificatória, seja na aprendizagem discente, seja na verificação das competências docentes e na qualidade institucional das agências educacionais. Este artigo classifica as formas de avaliação educacional a partir do eixo da exclusão/inclusão, atribuindo-as, respectivamente ao projeto neoliberal e aos projetos que lhe fazem resistência no campo educacional.

Palavras-chave: Educação. Avaliação educacional. Exclusão. Inclusão.

\section{NEOLIBERAL EVALUATION AND CONTRA-HEGEMONIC EVALUATION}

\section{ABSTRACT}

After it became a fashionable theme (from the early 1990s), the assessment was implemented in almost all countries of the world, under the hegemony of the summative or classificatory conception, be it in student learning or in the verification of teaching competence and institutional quality of educational agencies. This article classifies the forms of educational evaluation from the exclusion/inclusion axis, attributing them respectively to the neoliberal project and to the projects that resist to it in the educational field.

Keywords: Education. Educational avaluation. Exclusion. Inclusion.

\section{EVALUACIÓN NEOLIBERAL Y EVALUACIÓN CONTRA-HEGEMÓNICA}

\section{RESUMEN}

Después de que se convirtió en un tema de la moda (a partir de principios de la década de 1990), la evaluación se implantó en casi todos los países del mundo, bajo la hegemonía de la concepción "sumativa" o clasificatoria, ya sea en el aprendizaje discente, competencias docentes y en la calidad institucional de las agencias educativas. Este artículo clasifica las formas de evaluación educativa a partir del eje de la exclusión / inclusión, asignándolas, respectivamente al proyecto neoliberal ya los proyectos que le hacen resistencia en el campo educativo.

Palabras clave: Educación. Evaluation educativa. Exclusion. Inclusion. 